\title{
Assessing the Environmental Performance of Integrated Ethanol and Biogas Production
}

\author{
Michael Martin, Niclas Svensson, Jorge Fonseca \\ Linköping University, Environmental Technology and Management, Linköping, Sweden \\ * Corresponding author. Tel: +46 13281132, E-mail: michael.martin@liu.se
}

\begin{abstract}
As the production of biofuels continues to expand worldwide, criticism about, e.g. the energy output versus input and the competition with food has been questioned. However, biofuels may be optimized to increase the environmental performance through the concepts of industrial symbiosis. This paper offers a quantification of the environmental performance of industrial symbiosis in the biofuel industry through integration of biogas and ethanol processes using a life cycle approach. Results show that although increasing integration is assumed to produce environmental benefits in industrial symbiosis, not all impact categories have achieved this and the results depend upon the allocation methods chosen.
\end{abstract}

Keywords: Ethanol, Biogas, Industrial symbiosis, Environmental impacts, Biofuel

\section{Introduction}

The production of biofuels for transport has seen a large increase in the past few years to meet the onset of policies for increased production and use worldwide. However, with this onset, biofuels have met much criticism [1,2] which ranges from debates about the competition with food to the energy used to produce the biofuels [3]. Dissimilarities and criticism result primarily from different assumptions made, system boundaries used, technologies and the reference energy systems used in life cycle assessment of biofuel systems [4]. However, biofuel production encompasses large quantities of inputs and outputs and therefore, consideration must be made for the efficient use of resources for biofuel production industries [2] for which the environmental performance may be bettered and the flows of material and energy optimized [5]. One approach to do this is by employing concepts from industrial symbiosis.

Industrial symbiosis is a branch of industrial ecology focusing upon the inter-firm interactions aiming to engage traditionally separate industries to cooperate in a collective approach to create competitive advantages through resource exchanges and synergistic possibilities [6]. However in industrial symbiosis, benefits have rarely been quantified in the literature [7].

On the island of Händelö in Norrköping, Sweden, a unique bioenergy complex of symbiotic activities between the ethanol, biogas and energy system takes place [5]. However, using the concept of industrial symbiosis, these symbiotic activities could be further improved and more synergies could occur [5]. Could these synergies therefore lead to improved environmental performance and can they be quantified?

The aim of this research paper is to outline and present the environmental impacts and performance of several symbiotic activities, i.e. integrated scenarios, between the biogas and bioethanol facilities located on the island of Händelö, Norrköping. Using exchanges (i.e. synergies) between the biogas and bioethanol facilities, the environmental performance will be quantified using a life cycle approach of the synergies for different scenarios with increasing degrees of integration. 


\section{Methodology}

The environmental performance, i.e. environmental impacts, of symbiotic activities between biogas and ethanol production plants will be assessed by comparing different scenarios. Different degrees of integration will be tested from no integration at all (default) to all byproduct residues from the ethanol plant used in the biogas plant, as described in the subsequent section entitled, The Scenarios.

\subsection{System Description}

The production of biofuels takes place on the island of Händelö in Norrköping, Sweden. Ethanol is produced from a combination of wheat, barley and rye resulting in a number of byproducts such as Dried Distillers Grains with Solubles (DDGS), syrup and impurities. Biogas is produced through the anaerobic digestion of organic matter, in the scenarios e.g. wheat and barley and by-products of the ethanol facility. Conversion technologies and performance for the anaerobic digestion and fermentation processes have been obtained from the companies, along with material and energy flows [5,8-10].

The assessment takes the ethanol plant as starting point and keeps the ethanol fuel output static whereas all of the other inputs and outputs for that plant and the biogas plant are allowed to vary in accordance with the scenarios described below. This approach was chosen in order to reflect upon the importance of size differences between the plants but also of the potential implications of larger by-product exchanges between the two plants.

\subsection{Tools and Impact Categories}

A life cycle approach is applied to each scenario separately from a cradle-to-gate perspective. All life cycle assessment calculations of environmental impacts have been performed using the software package SimaPro v. 7.2. The life cycle impact assessments have been conducted using the EPD 2007 [11] method. This method was chosen due to its recommendation by the Swedish Environmental Management Council and providing a wide array of environmental impact categories, e.g. global warming potential (GWP), acidification, eutrophication and the use of non-renewable resources.

\subsection{Allocation Procedures}

By-products and the energy and emissions associated with their use have been taken care of by the use of two separate methods in this paper, including energy allocation and system expansion $[4,8]$. The energy content of these by-products has been computed for the lower heating value of the DM contained in each fraction. Energy allocation figures used for each scenario can be seen in Tables 1-2.

Table 1: Ethanol Production Allocation for Major Products and By-Products [8]

\begin{tabular}{ccccccc}
\hline $\begin{array}{c}\text { Product/ } \\
\text { By- } \\
\text { Product }\end{array}$ & $\begin{array}{c}\text { DM Content } \\
(\%)\end{array}$ & $\begin{array}{c}\text { Default } \\
\text { Scenario }\end{array}$ & $\begin{array}{c}\text { Existing } \\
\text { Scenario }\end{array}$ & Scenario 1 & Scenario 2 & Scenario 3 \\
\hline Ethanol & - & $70,7 \%$ & $70,7 \%$ & $70,7 \%$ & $60,3 \%$ & $60,3 \%$ \\
DDGS & 90 & $21,7 \%$ & $21,7 \%$ & $21,7 \%$ & - & - \\
Syrup & 27 & $5,6 \%$ & $5,6 \%$ & $5,6 \%$ & - & - \\
Impurities & 86 & $2,0 \%$ & $2,0 \%$ & $2,0 \%$ & - & - \\
Stillage & 16 & - & - & - & $39,7 \%$ & $39,7 \%$ \\
\hline
\end{tabular}


Table 2: Biogas Production Allocation for Major Products and By-Products [8]

\begin{tabular}{cccccc}
\hline $\begin{array}{c}\text { Product/ } \\
\text { By-Product }\end{array}$ & $\begin{array}{c}\text { Default } \\
\text { Scenario }\end{array}$ & $\begin{array}{c}\text { Existing } \\
\text { Scenario }\end{array}$ & Scenario 1 & Scenario 2 & Scenario 3 \\
\hline Biogas & $31,3 \%$ & $35,7 \%$ & 35,7 & $35,7 \%$ & $33,7 \%$ \\
$\begin{array}{c}\text { Biogas to } \\
\text { Ethanol }\end{array}$ & - & - & - & - & $2,0 \%$ \\
Biofertilzer & $68,7 \%$ & $64,3 \%$ & 64,3 & $64,3 \%$ & $64,3 \%$ \\
\hline
\end{tabular}

System expansion, also known as substitution, has also been conducted to account for the replacement of by-products produced [4]. System expansion for the default and existing scenarios of the ethanol plant include the use of stillage products for fertilizers and animal fodder applications. Fodder replacement by DDGS and syrup in dry matter content (DM) has been assumed to replace Brazilian soy meal and European barley in the amounts of 0,4 $\mathrm{kg}$ $\mathrm{DM}$ and 0,6 kg DM [2]. Fertilizer nutrients replaced by biogas digestate per ton is assumed to replace $8 \mathrm{~kg} \mathrm{~N}, 5 \mathrm{~kg} \mathrm{NH}_{4}, 1 \mathrm{~kg} \mathrm{P}$ and $1,5 \mathrm{~kg} \mathrm{~K}$ per ton of produced digestate [8]. Furthermore, the lower heating value (LHV) for dried stillage has been assumed to be the same as that for the digestate [3] due to limited data availability.

\subsection{The Scenarios}

Scenarios have been produced to test and quantify the environmental performance of several different material and energy exchanges between the bioethanol and biogas production plants as aforementioned. Each scenario is tested using both the energy allocation and system expansion methods to account for energy and replacement of processes from the by-products $[12,13]$. The outputs have been expressed using the LHV for both biogas and ethanol, $50 \mathrm{MJ} / \mathrm{kg}$ and 28,87 MJ/kg respectively.

\subsubsection{Default Scenario}

The default scenario will show the impacts of two stand alone plants with no integration. The two plants use respective inputs of wheat, barley and triticale for their production processes. In terms of biofuel production output, the main products are $17 \mathrm{TJ}$ of biogas and $1314 \mathrm{TJ}$ of ethanol. All inputs and outputs of raw material, by-products, etc. are based on the aforementioned biofuel outputs [8]. The default scenario has been used to compare to the existing scenario in order to compare the environmental impacts of current practice with that of a stand alone system.

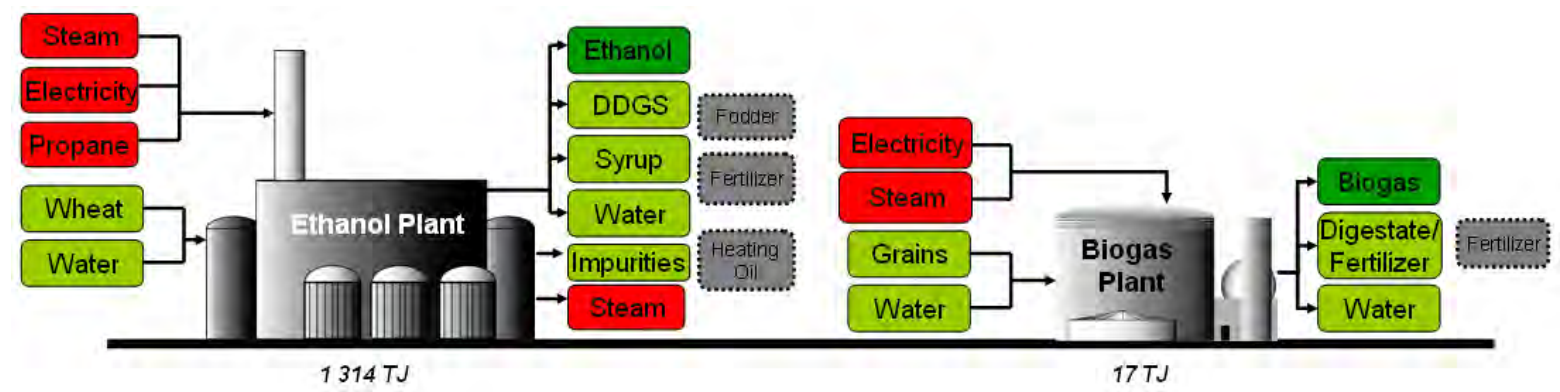

Fig. 1: Default Scenario. Note the avoidance of fodder and fertilizers from the ethanol and biogas plants for the system expansion have been included [8]. 


\subsubsection{Existing Scenario and Scenario 1}

The existing scenario is similar to the production process used pre-2009 on the island of Händelö. The exchange of thin stillage is used to produce biogas at the neighboring biogas plant. Furthermore, as the thin stillage is sent to the biogas plant at a temperature of around $70^{\circ} \mathrm{C}$, it must be cooled to around $38^{\circ} \mathrm{C}$ for anaerobic digestion and thus electrical fans are used to cool the substrate and no external process heat is required [14,15]. The output of the system in biofuel is again $17 \mathrm{TJ}$ of biogas and $1314 \mathrm{MJ}$ of ethanol for which all inputs and outputs are based [8]. Scenario 1 is similar to the existing scenario, however in Scenario 1 the impurities (consisting primarily of husks and filtered grains) are also sent to produce biogas. This therefore raises the output of biogas production and digestate, requiring more electricity and water for the digestion and upgrading processes respectively (ibid.).

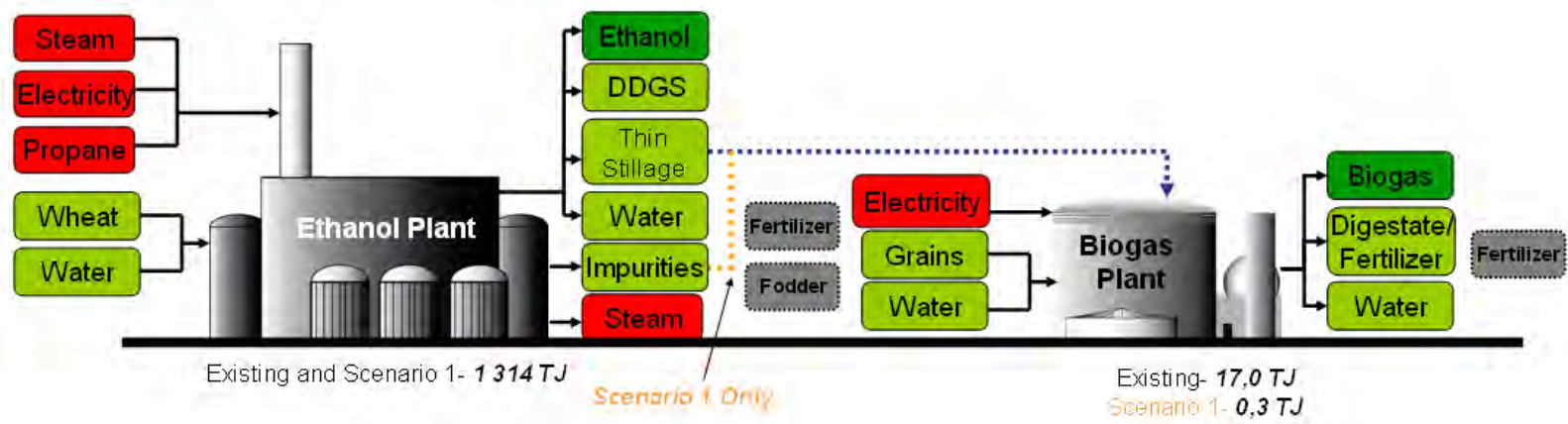

Fig. 2: Existing Scenario and Scenario 1. Note the avoidance of fodder and fertilizers for the system expansion have been included [8].

\subsubsection{Scenarios 2 and 3}

In Scenarios 2 and 3, it is assumed that all the stillage is sent to the biogas plant for anaerobic digestion. By doing so the ethanol plant can save a large input of energy, roughly $35 \%$ less energy [16] from the dryers and handling equipment for fodder production. Scenario 2 and 3 are similar, in that they both use stillage for biogas production. However, Scenario 3 differs in the fact that biogas replaces propane in the ethanol production plant for odor control [14]. Similar to the existing scenario, the stillage is sent to the biogas plant at a higher temperature than necessary for the process and electrical fans are used to cool the substrate, requiring no external process heat. The production of biogas has now been increased to $464 \mathrm{TJ}$ in Scenario 2 and $438 \mathrm{TJ}$ in Scenario 3 (accounting for the use of $26 \mathrm{TJ}$ of biogas for ethanol production) while the production of ethanol remains the same as in the default and existing scenarios [8].

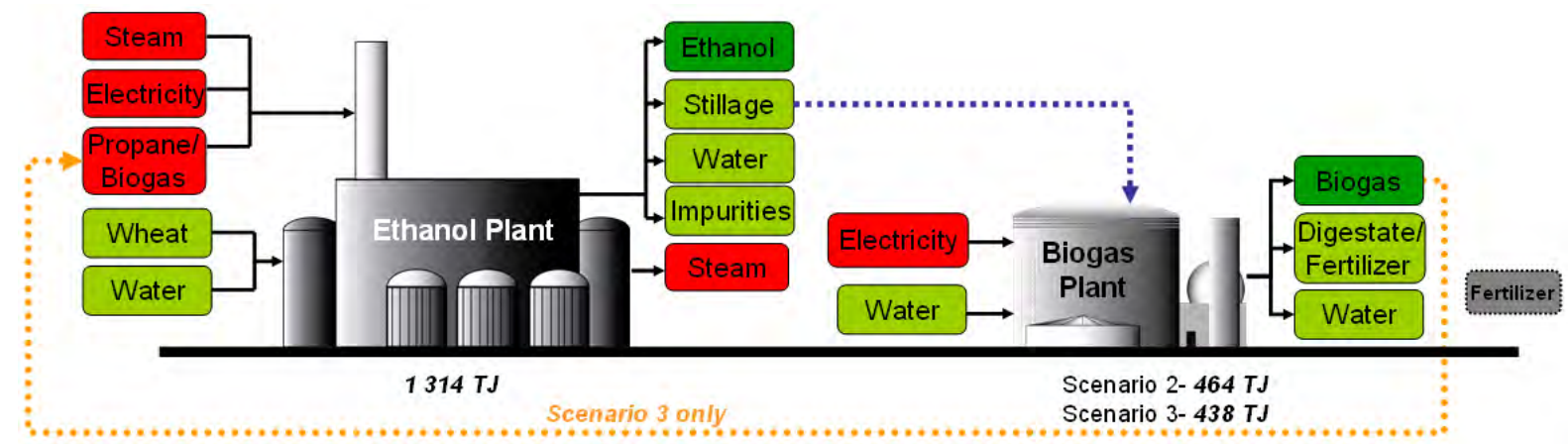

Fig. 3: Scenarios 2 \& 3. Note that in Scenario 3, the biogas is used in place of propane (denoted by an orange dashed line). The figure also includes avoided fertilizers for the system expansion method [8]. 


\subsection{Data Inventory}

Data has been obtained from the biofuel production firms of Händelö, Norrköping in Sweden. Production figures are relevant for pre-2009 conditions for the default and existing scenarios [8-10,14,15]. When data has been limited or unavailable, comparable data from the Ecoinvent database v. 2.1 has been used for e.g. specific cultivation, fertilizers and transportation data. Energy for the system is provided from the Swedish electricity production system based primarily upon hydropower and nuclear power [17]. Process heat, in the form of steam is provided from a neighboring combined heat and power plant fueled by biomass $[8,9,18]$. Grains are transported within the Östergötland County to the island of Händelö, with an average distance of $100 \mathrm{~km}$. Transportation of the various raw materials between the neighboring biogas and ethanol production firms is assumed to have an average distance of 5 $\mathrm{km}$. The biofertilzer transport has been assumed to be on average $33 \mathrm{~km}$ [8].

\section{Results and Discussion}

The environmental performance of the integrated systems from the aforementioned scenarios can be seen in Figs. 4-6. These figures show the global warming potential, impacts from acidification and eutrophication as well as the use of non-renewable fuel. A discussion of the results will follow each figure in the subsequent sections. Further details can be found in Martin et al. [8]. The following notation has been used to describe each scenario in the figures:

D-EA: Default Scenario (Energy Allocation)

D-SE: Default Scenario (System Expansion)

E-EA:Existing Scenario (Energy Allocation)

E-SE: Existing Scenario (System Expansion)

1-EA: Scenario 1 (Energy Allocation)

1-SE: Scenario 1 (System Expansion)
2-EA: Scenario 2 (Energy Allocation)

2-SE: Scenario 2 (System Expansion)

3-EA: Scenario 3 (Energy Allocation)

3-SE: Scenario 3 (System Expansion)

\subsection{Global Warming Potential}

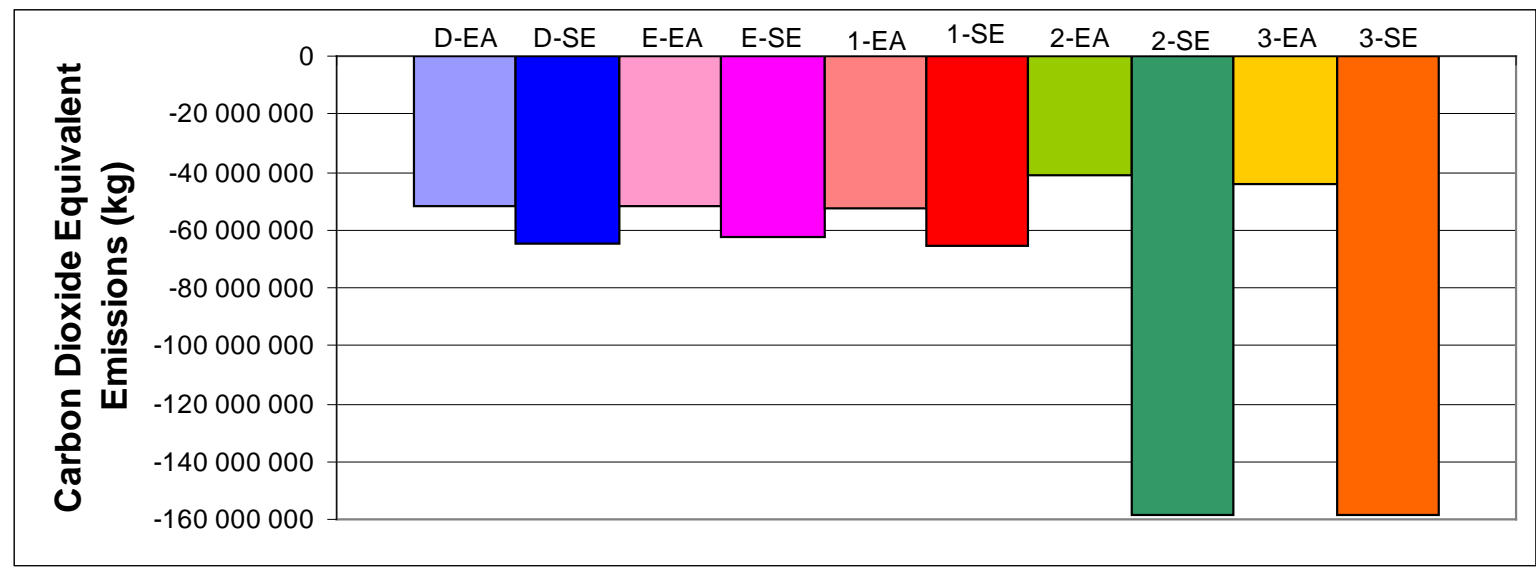

Fig. 4: Global Warming Potential of the different Scenarios measured in $\mathrm{kg}$ of $\mathrm{CO}_{2}$-equivalent. [8]

From Fig. 4 it is apparent that there are some differences between each scenario, with the system expansion method producing the largest variations. The benefits related to the global warming potential from the energy allocation method do not to follow the trend found in the system expansion method with increasing integration of the biogas and ethanol systems, i.e. increased benefits with increasing integration. It can be seen that the systems with the largest integration also have a lower share of the impacts and benefits associated with their outputs 
based on how the energy is allocated between the products and by-products. This means that while the systems may be increasingly integrated, the outputs receive a lower share of the benefits [8]. Furthermore, when all stillage is used for biogas production this increases the production of biogas thus increasing the use of electricity, water and transportation of biofertilizer and the stillage to and from the biogas facility. These increases therefore lead to reduced benefits for Scenarios 2 and 3 in the energy allocation. With increasing integration of the systems there are also larger impacts associated with increased transportation and electricity consumption (ibid.) thus decreased.

In the system expansion method, all benefits and burdens from the systems are allocated to the main outputs, ethanol and biogas. However, the use and substitution of processes associated with the by-products are also taken into account. Increasing integration tends to therefore produce larger benefits to the system with increasing integration, with exception to the existing scenario. This is primarily a result of the increase in biofertilizer replacing conventional fertilizers, though the biofertilizer production is reduced slightly in the existing scenario. When comparing the existing scenario with the default scenario, the default scenario has a larger benefit due to a larger input of grains. With the current system boundaries, cradleto-gate, the grain thus sequestrates a large amount of carbon dioxide [8]. Consistent with the energy allocation methods, increasing integration of the systems leads to larger impacts associated with increased transportation and electricity consumption. Nonetheless, these increased impacts are consumed by the benefits to the system from the system expansion (ibid.). In Scenarios 2 and 3, by using the stillage and not adding extra heat for e.g. drying for DDGS production, these scenarios gain further benefits from less heat and water use. Scenario 3 can be seen to have slightly higher benefits in both allocation methods due primarily to the replacement of propane with biogas.

\subsection{Non-Renewable Energy Consumption}

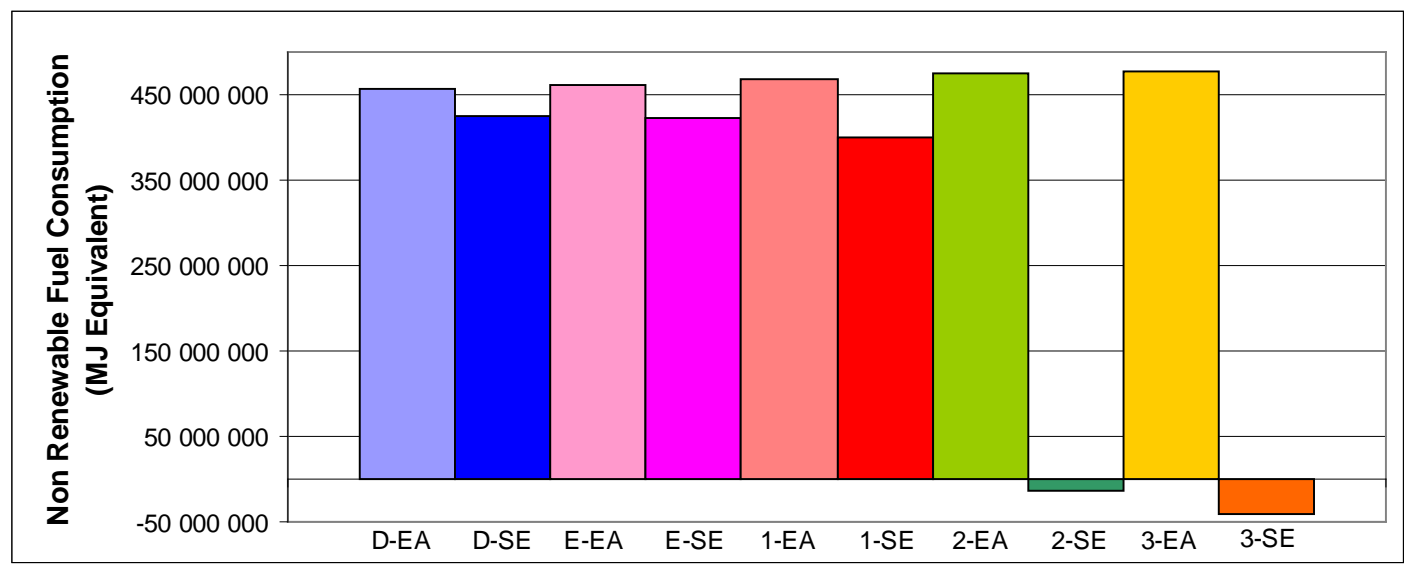

Fig. 5: Consumption of Non-renewable Energy in MJ-equivalent for the different scenarios. [8]

Another important aspect to show is the consumption of nonrenewable energy. The general trend for the consumption of non-renewable fuels for increasing integration is an increase in the energy allocation scenarios and a decrease in the system expansion method. An increase in the energy allocation scenarios is due to increased transportation of stillage and biofertilizer. The decrease of non-renewable fuel consumption with increasing integration in the system expansion scenarios arises from the enhanced quantities of biofertilzer produced, thus replacing conventional fertilizers. 


\subsection{Acidification and Eutrophication}

In order to show an array of local and global impacts, the acidification and eutrophication impacts have also been documented in Fig. 6.

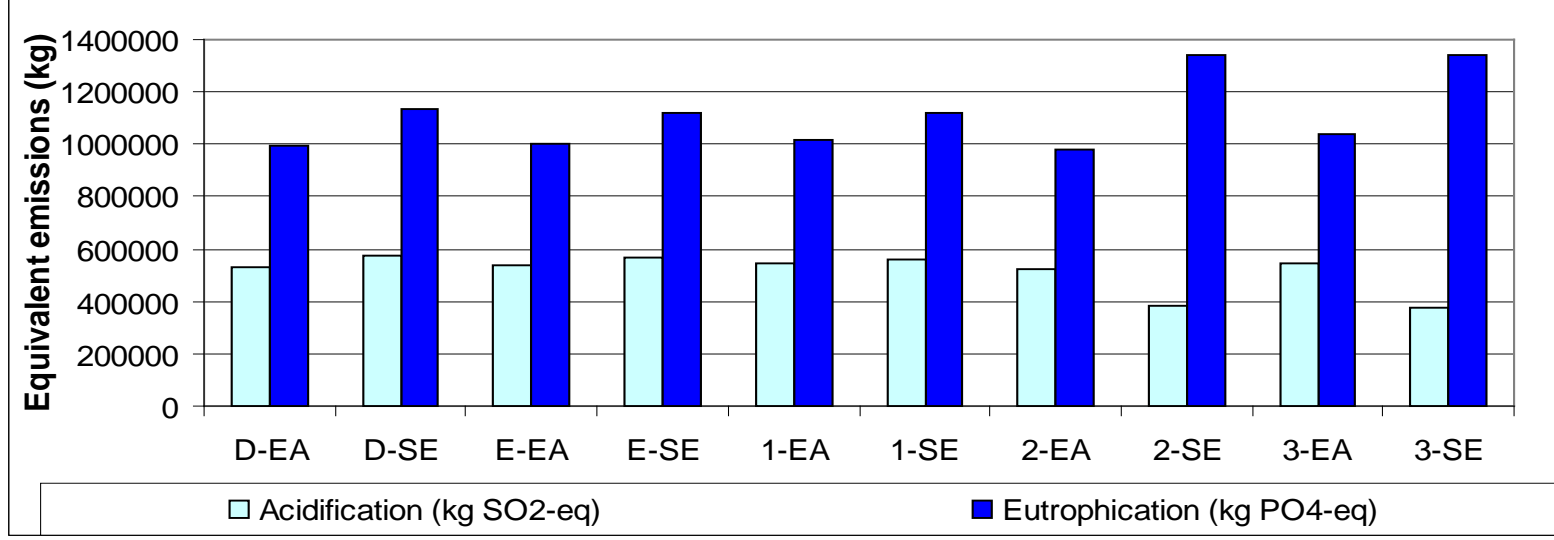

Fig. 6: Impacts in kilograms of equivalent $\mathrm{SO}_{2}$ and $\mathrm{PO}_{4}$ for Acidification and Eutrophication. [8]

Fig. 6 shows the Eutrophication potential for the allocation methods of each scenario. The increased integration of biogas and ethanol from the default scenario to the full use of stillage tends to correspond to larger eutrophication impacts in all cases except for the energy allocation method in Scenario 2 and when accounting for the use of biogas instead of propane in the system expansion method for Scenario 3. Once again this is primarily a result of the increase in transportation required with increased integration [8].

Correspondingly the impacts from acidification tend to increase slightly using energy allocation, with exception to Scenario 2. This stems from a slightly reduced impact from the transportation and cultivation of grains in this scenario while Scenario 3 thereafter increases. There is a general decrease in emissions of equivalent $\mathrm{SO}_{2}$ for the system expansion method due to the reduction of fertilizer by increasing integration, and correspondingly increasing biofertilizer production, replacing conventional fertilizers [8].

\section{Conclusions}

The integration of biogas and ethanol production can be seen from this paper as a complex system. Although the $\mathrm{CO}_{2}$-equivalent emissions may be further reduced by increasing the integration of the biofuel plants in the system expansion case, the energy allocation method proves opposite results. Furthermore local impacts such as acidification and eutrophication should be considered, which may increase with increasing integration. Therefore the allocation method chosen is crucial for taking into account energy and impacts embodied in by-products and replaced processes and may lead to converse results. The removal and addition of processes, materials and energy can have both improvements and rebound effects for the system. These impacts could possibly be resolved in the biogas plant by more efficient upgrading processes, transportation of stillage by pipeline and a more efficient cooling system for the incoming stillage as well as internal optimization at the ethanol plant.

This report thus shows that there is a need to understand the impacts produced from biofuel production and industrial symbiosis activities. Symbiotic activities may lead to environmental performance benefits, though the choice of impact category and allocation method is crucial when comparing local vs. global impacts. Nonetheless, this study may open for further work on the quantification of integrated biofuel production processes and other symbiotic activities. 


\section{References}

[1] J.W. Ponton, Biofuels: Thermodynamic sense and nonsense, Journal of Cleaner Production, 17, 2009, pp.896-9.

[2] P. Börjesson, Good or bad bioethanol from a greenhouse gas perspective - What determines this? Applied Energy, 86, 2009, pp.589-94.

[3] P. Börjesson, L.M. Tufvesson, Agricultural crop-based biofuels - resource efficiency and environmental performance including direct land use changes, Journal of Cleaner Production, In Press, Corrected Proof, 2010.

[4] E. van der Voet, R.J. Lifset, L. Luo, Life-cycle assessment of biofuels, convergence and divergence, Biofuels, 1, 2010, pp.435-49.

[5] M. Martin, Industrial Symbiosis for the Development of Biofuel Production, Licentiate Thesis, 2010, pp.1-53.

[6] M.R. Chertow, Industrial symbiosis: Literature and taxonomy, Annual Review of Energy and the Environment, 25, 2000, pp.313-37.

[7] M. Karlsson, A. Wolf, Using an optimization model to evaluate the economic benefits of industrial symbiosis in the forest industry, Journal of Cleaner Production, 16, 2008, pp.1536-44.

[8] M. Martin, J. Fonseca, N. Svensson, A. Helgstrand, Assessing the Environmental Performance of Integrated Biogas and Ethanol Production: Quantifying Industrial Symbiosis in the Biofuel Industry, LIU-IEI-R-- 10/0115--SE, 2010, pp.1-50.

[9] Lantmännen Agroetanol AB, Lantmännen Agroetanol AB Homepage, 2009.

[10] Svensk Biogas AB, Svensk Biogas AB Homepage, 2009.

[11]Environdec, The international EPD system- a communication tool for international markets, 2009.

[12] European Union, Directive 2009/28/EC of the European Parliament and of the Council of 23 April 2009 on the promotion of the use of energy from renewable sources and amending and subsequently repealing Directives 2001/77/EC and 2003/30/EC, L140/1662: Official Journal of the European Union, 2009.

[13]ISO, ISO 14040:2006 Environmental management-life cycle assessment-principles and framework ISO 14044: 2006, Environmental Management-Life Cycle AssessmentRequirements and Guidelines, 2006.

[14] P. Paulsson, Energianalys av etanolproduktion, Master of Science Thesis, SLU, 2007.

[15] J.A. Fonseca, Assessing the Environmental Impacts of Synergies between the Ethanol and the Biogas Industries, Master of Science Thesis, Linköping University, 2010.

[16]J.D. Murphy, N.M. Power, How can we improve the energy balance of ethanol production from wheat? Fuel, 87, 2008, pp.1799-806.

[17]S. Bernesson, D. Nilsson, P. Hansson, A limited LCA comparing large- and small-scale production of ethanol for heavy engines under Swedish conditions, Biomass and Bioenergy, 30, 2006, pp.46-57.

[18] E.ON Värme Sverige, E.ON i världsunikt energikombinat, 2009. 